\title{
Effect of acidity of rapeseed oil on its transesterification
}

Jiří Kwiecien, Martin Hájek ${ }^{*}$, František Skopal

\author{
All authors: \\ Department of Physical Chemistry, Faculty of Chemical Technology, University of \\ Pardubice, Pardubice, Czech Republic
}

Postal address:

Department of Physical Chemistry, Faculty of Chemical Technology, University of

Pardubice, nám Čs. legií 565, 53210 Pardubice, Czech Republic.

Phone: +420 466037 047, fax: +420 466037068

e-mail: jiri.kwiecien@post.cz

martin.hajek2@upce.cz

frantisek.skopal@upce.cz

* corresponding author 


\section{Summary}

The aim of this work is to study the transesterification of vegetable oils with a high acid number. Rapeseed oil was used as the raw material and its acid number was changed by the adding of oleic acid (from 0.89 to $12.25 \mathrm{mg} \mathrm{KOH} / \mathrm{g}$ ). Methanol was used for transesterification (molar ratio of oil to methanol 1:6) and potassium hydroxide was used as a catalyst. After the reaction time, the residue of catalyst was neutralized by gaseous carbon dioxide and methanol excess was removed. After the separation of two phases, each of them was analyzed (in ester phase: yield, content of methylester and acid number; in glycerol phase: yield, density, viscosity, content of glycerol, soaps, methylester, potassium carbonate and hydrogen carbonate). The obtained data was compared with theoretical material balances and effect on saponification of oil was calculated. The results show that the yield of methylester (biodiesel) is significantly affected by higher acid number, as well as enhanced soap formation. On the other hand, the conversion of the oil and acid number of the ester phase remain at constant values in studied borders.

\section{Keywords:}

biodiesel, transesterification, acid number, yield, saponification 


\section{Introduction}

Biodiesel is a renewable energy source for mobile combustion engines with many benefits against fossil diesel. It is a non-toxic substance; its combustion does not lead to green-house effect. As shown in studies on contemporary motor types (Altın et al., 2001; Kegl, 2008), biodiesel is a direct substituent for fossil diesel.

The bases of raw materials are vegetable oils and animal fats. Vegetable oils such as rapeseed oil, sunflower oil, soya oil etc. are a good opportunity for agriculture, but the soil used for growing these plants can not be used immediately for food production. Another way is using of waste oils and fats.

In present technological processes, methanol as a reaction partner and the hydroxides of alkaline metals as catalysts are mostly used (Vicente et al., 2004). This is probably the cheapest method for conversion of oil to biodiesel. Typical reaction conditions are: molar ratio methanol:oil $=6: 1$, reaction temperature at $40-60{ }^{\circ} \mathrm{C}$, reaction time $60-100$ minutes, catalyst amount approx. 1 wt-\% per oil. But these catalysts cause saponificaton of oil and so it is sensitive to oil quality. Waste cooking oils with high acid number need even the use of an acid catalyst to avoid the saponification. Using of acids as catalyst is now under intensive investigation (Jacobson et al., 2008) as well as transformation of fatty acids to methylesters (Marchetti and Errazu, 2008). Other transesterification methods are based on heterogeneous catalysts (López et al., 2005) and enzymatic transformation (Iso et al., 2001). The reaction without catalyst proceeds in supercritical state, under high pressure and temperature (Demirbas, 2008).

The goal of this work is to study the effect of acidity of rapeseed oil on its basically catalyzed methanolysis. 


\section{Theory}

Various amounts of oleic acid were added to rapeseed oil to simulate the behaviour of natural plant oil with higher acid number. Oleic acid is the most abundant acid (55-65 wt\%) in the oil composition (Mittelbach and Remschmidt, 2004).

Biodiesel was prepared by methanolysis (molar ratio of methanol to oil 6:1) catalyzed by potassium hydroxide. The transesterification reaction proceeded in heterogeneous mixture (RRM) after mixing of oil with methanolic solution of potassium hydroxide. Before the surplus of methanol was removed, the catalyst was neutralised by gaseous carbon dioxide dosage not to drive the reaction back. The carbon dioxide and $\mathrm{KOH}$ form carbonates. Using of $\mathrm{CO}_{2}$ is described in (Skopal et al., 2001). Besides of catalytic function, the $\mathrm{KOH}$ allows the side saponification reaction of oil and methylester, and therefore, decreases the methylester yield.

The RRM separates spontaneously after demethanolisation into the polar (Glycerol Phase - GP) and apolar phase (Ester Phase - EP) - biodiesel. Besides glycerol, the GP consists of water, soaps, salts, methylester and methanol. The EP is formed mainly by methylesters of fatty acids and small rest of glycerides and water.

\subsection{Material balances}

For better understanding of studied system, some material balances can be made. Input amounts of raw materials and their quality as well as output product analysis are described.

\subsubsection{Balances of soaps}

The free fatty acids (FFA) present in raw oil consume the catalyst. The content of FFAs is characterized by the acid number (an, mg KOH/g of oil). To simplify the 
calculations, mean molar weight of free fatty acids is considered the same as molar weight of oleic acid.

The amount of the soaps $m_{\mathrm{s}}^{\text {start }}$ originated from the FFAs is:

$$
m_{\mathrm{S}}^{\text {start }}=\frac{a n}{1000} \cdot \frac{M_{\mathrm{S}}}{\mathrm{M}_{\mathrm{KOH}}} \cdot m_{\mathrm{N}} \text {, }
$$

this needs extra $\mathrm{KOH}$ for their neutralisation:

$$
m_{\mathrm{KOH}}^{\text {neut. }}=m_{\mathrm{S}}^{\text {start }} \cdot \frac{M_{\mathrm{KOH}}}{M_{\mathrm{S}}},
$$

where an ( $\mathrm{mg} \mathrm{KOH} / \mathrm{g}$ ) stands for acid number of the oil, $M_{\mathrm{S}}$ is the molar weight of

soaps, $M_{\text {Кон }}$ represents the molar weight of $\mathrm{KOH}$ and $m_{\mathrm{N}}(\mathrm{g})$ is the batched amount of oil.

The entire amout of soaps $m_{\mathrm{s}}$, determined experimentally, can be calculated from GP analysis (3).

$$
m_{\mathrm{S}}=\xi_{\mathrm{S}} \cdot m_{\mathrm{GP}},
$$

where $\xi_{\mathrm{S}}$ is the mass fraction of soaps in GP and $m_{G P}(\mathrm{~g})$ is the total mass of GP.

The mass of soaps formed by saponification of oil and methylesters $m_{\mathrm{S}}^{\mathrm{r}}$ must be the difference between entire experimentally determined amount of soaps $m_{\mathrm{S}}$ and soaps originated from the FFA, $m_{\mathrm{s}}^{\text {start }}(4)$.

$$
m_{\mathrm{S}}^{\mathrm{r}}=m_{\mathrm{S}}-m_{\mathrm{S}}^{\mathrm{start}}=\xi_{\mathrm{S}} \cdot m_{\mathrm{GP}}-\frac{a n}{1000} \cdot \frac{M_{\mathrm{S}}}{\mathrm{M}_{\mathrm{KOH}}} \cdot m_{\mathrm{N}}
$$

\subsubsection{Balances of oil, theoretical yield of methylester}

Let us assume that the rapeseed oil (RO) consists only of triglycerides (TG), free fatty acids and water.

It is possible to calculate the mass of FFAs from the acid number as: 
$m_{\mathrm{FFA}}^{\text {start }}=\frac{a n}{1000} \cdot \frac{M_{\mathrm{FFA}}}{\mathrm{M}_{\mathrm{KOH}}} \cdot m_{\mathrm{N}}$.

Water mass fraction $\xi_{\mathrm{H}_{2} \mathrm{O}}^{\mathrm{RO}}$ was determined by the titration, see chapter 3.2.

Then, equation (6) for the mass of triglycerides $m_{\mathrm{TG}}$ in the batch can be written

$$
m_{\mathrm{TG}}=m_{\mathrm{N}}-m_{\mathrm{FFA}}^{\mathrm{start}}-m_{\mathrm{H}_{2} \mathrm{O}}^{\mathrm{RO}}=\left(1-\frac{a n}{1000} \cdot \frac{M_{\mathrm{FFA}}}{\mathrm{M}_{\mathrm{KOH}}}-\xi_{\mathrm{H}_{2} \mathrm{O}}^{\mathrm{RO}}\right) \cdot m_{\mathrm{N}} .
$$

$m_{\mathrm{TG}}$ means the amount of TG capable for transesterification in the batch.

Assuming no triglycerides and methylester saponification and the stochiometric

transesterification reaction (ideal): $\mathrm{TG}+3 \mathrm{CH}_{3} \mathrm{OH} \rightarrow 3 \mathrm{ME}+$ glycerol,

the theoretical mass of the ester phase $m_{\mathrm{EP}}^{t, \text { id }}$ at complete conversion is given by the relation

$$
m_{\mathrm{EP}}^{t, \mathrm{id}}=m_{\mathrm{TG}} \cdot \frac{3 M_{\mathrm{ME}}}{M_{\mathrm{TG}}}
$$

The mass of EP calculated according (7) is the maximum obtainable one and our experimental results were compared with it.

The experimental mass of EP is always smaller, because the saponification reaction takes place and some methylester dissolves in GP. This mass of methylester in GP $\left(m_{\mathrm{ME}}^{\mathrm{GP}}\right)$ can be estimated by analysis of GP. The mass of TG saponificated by the side reaction is

$$
m_{\mathrm{TG}}^{\mathrm{sap} .}=\frac{1}{3} \cdot M_{\mathrm{TG}} \cdot\left(\frac{m_{\mathrm{GP}} \cdot \xi_{\mathrm{s}}}{M_{\mathrm{S}}}-\frac{a n}{1000} \cdot \frac{m_{\mathrm{N}}}{M_{\mathrm{KOH}}}\right) .
$$

Therefore the theoretical (calculated) mass of the whole EP, i. e. mass of methylesters $m_{\mathrm{ME}}^{t}$ after the transesterification and the separation of GP is given, using (6) and (8), by the relation 


$$
m_{\mathrm{ME}}^{t}=\frac{3 M_{\mathrm{ME}}}{M_{\mathrm{TG}}} \cdot\left(m_{\mathrm{TG}}-m_{\mathrm{TG}}^{\text {sap. }}\right)-m_{\mathrm{ME}}^{\mathrm{GP}}=\frac{3 M_{\mathrm{ME}}}{M_{\mathrm{TG}}} \cdot\left(m_{\mathrm{TG}}-m_{\mathrm{TG}}^{\mathrm{sap}}\right)-m_{\mathrm{GP}} \cdot \xi_{\mathrm{ME}}^{\mathrm{GP}} \cdot
$$

For presentation of transesterification result, we always use the transesterification yield which is defined as mass ratio of obtained amount of EP or GP to the initial amount of the oil.

\section{Materials and methods}

\subsection{Used chemicals and raw materials}

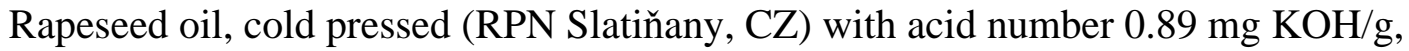
water content 500 ppm. Potassium hydroxide (Lachema Neratovice, CZ), 84 wt-\% purity. Oleic acid p. a. (Lachema Neratovice, CZ). Methanol, technical grade (Lach-ner, CZ). Demineralised water from reverse osmosis (AQUL 21®, Aqual). Carbon dioxide (Linde Gas, CZ), for grocery purpose.

\subsection{Analytical methods}

Determination of water content; Karl Fischer titration (automatic titrator 736 GP Titrino ${ }^{\circledR}$, Metrohm, Switzerland).

Determination of methylester content: GC analysis, determination of glycerides content: HPLC isocratic analysis. Both methods are described in detail in (Komers et al., 1998).

Glycerol in the GP was determined by iodometry (Jureček, 1957).

Density of GP was measured pycnometrically and viscosity at $40{ }^{\circ} \mathrm{C}$ was measured by Ostwald’s viscosimeter. 
Mass fractions of potassium carbonate, potassium hydrogen carbonate and soaps in GP were calculated from determination of alkality in GP and volumetric determination of carbon dioxide.

The sample of GP was titrated by $\mathrm{HCl}(0.1 \mathrm{M})$ at the potenciometric indication in methanolic solution. The titration curve has two steps represented by volumes of standard solution of $\mathrm{HCl} V_{1}$ and $V_{2}$. The first step belongs to the reaction between potassium carbonate and $\mathrm{HCl}$ to form hydrogen carbonate: $\mathrm{CO}_{3}^{2-}+\mathrm{H}^{+} \rightarrow \mathrm{HCO}_{3}^{-}$.

The second step represents two reactions: hydrogen carbonate to carbon dioxide and soaps (KA) to fatty acids (HA): $\mathrm{HCO}_{3}^{-}+\mathrm{H}^{+} \rightarrow \mathrm{CO}_{2}+\mathrm{H}_{2} \mathrm{O}, \mathrm{KA}+\mathrm{H}^{+} \rightarrow \mathrm{K}^{+}+\mathrm{HA}$.

The potassium hydrogen carbonate occurs in GP as well as potassium carbonate. The sum of these two compounds has to be determinated by another method. In this case by volumetric determination of carbon dioxide liberated from the sample by excess of phosporic acid. Gained volume of $\mathrm{CO}_{2}$ was recalculated to molar amount with respect to laboratory pressure and temperature.

Then the mass fraction of potassium carbonate ( $\mathrm{w} / \mathrm{w}$ ) was calculated according to (10) and potassium hydrogen carbonate according to (11).

$$
\begin{aligned}
& \xi_{\mathrm{K}_{2} \mathrm{CO}_{3}}=\frac{C_{\mathrm{HCl}} \cdot V_{1} \cdot 10^{-3} \cdot M_{\mathrm{K}_{2} \mathrm{CO}_{3}}}{m_{\mathrm{GP}}^{\text {sample1 }}}, \\
& \xi_{\mathrm{KHCO}_{3}}=\frac{M_{\mathrm{KHCO}_{3}}}{m_{\mathrm{GP}}^{\text {sample2 }}} \cdot\left(\frac{p \cdot V_{\mathrm{CO}_{2}} \cdot 10^{-6}}{R \cdot T}-\frac{\xi_{\mathrm{K}_{2} \mathrm{CO}_{3}} \cdot m_{\mathrm{GP}}^{\text {sample2 }}}{M_{\mathrm{K}_{2} \mathrm{CO}_{3}}}\right),
\end{aligned}
$$

where $V_{\mathrm{CO}_{2}}$ is the volume of carbon dioxide, $m_{\mathrm{GP}}^{\text {sample1 }}$ is the mass of the sample for acidimetric titration, $m_{\mathrm{GP}}^{\text {sample2 }}$ the mass of sample for volumetric determination of carbon 
dioxide, $p$ is the atmospheric pressure in pascals and $T$ is the absolute laboratory temperature. Symbol $C_{\mathrm{HCl}}$ stands for accurate concentration of water solution of hydrochloric acid. The $R$ is universal gas constant. All volumes are in millilitres.

Then the mass fraction (w/w) of soaps is the difference between volumes $V_{2}$ and $V_{1}$ minus concentration of potassium hydrogen carbonate:

$$
\xi_{\mathrm{S}}=\frac{c_{\mathrm{HCl}} \cdot\left(V_{2}-V_{1}\right) \cdot 10^{-3} \cdot M_{\mathrm{S}}}{m_{\mathrm{GP}}^{\text {sample1 }}}-\xi_{\mathrm{KHCO}_{3}} \cdot \frac{M_{\mathrm{S}}}{M_{\mathrm{KHCO}_{3}}} \cdot \frac{m_{\mathrm{GP}}^{\text {sample2 }}}{m_{\mathrm{GP}}^{\text {sample } 1}}
$$

The mass fraction of methylester in GP was determined indirectly. If hydrochloric or phosporic acid is added to the sample of GP, the arised fatty acids with methylester make a separate apolar layer (AL). From the knowledge of acid number of this layer and soaps content in GP it is possible to calculate the mass fraction of methylester as

$$
\xi_{\mathrm{ME}}^{\mathrm{GP}}=\frac{\xi_{\mathrm{S}}}{M_{\mathrm{S}} \cdot c_{\mathrm{KOH}} \cdot V_{\mathrm{KOH}}} \cdot\left(m_{\mathrm{AL}}-c_{\mathrm{KOH}} \cdot V_{\mathrm{KOH}} \cdot M_{\mathrm{FFA}}\right),
$$

where $m_{\mathrm{AL}}(\mathrm{g})$ is the mass of the apolar layer for titration, $V_{\mathrm{KOH}}$ is volume (L) of standard ethanolic solution of potassium hydroxide having a concentration of $c_{\mathrm{KOH}}(\mathrm{mol} / \mathrm{L})$. Acid number of oil, EP and AL were determined by alkalimetric titration according to the norm EN 14214:2003.

\section{Experimental}

\subsection{Transesterification procedures}

The biodiesel preparation took place in the batch reactor, the round-bottomed flask equipped with the stirrer (Heidolph® ${ }^{\circledR}$ RZR 2041). Approximately 450 grams of acidified rapeseed oil was poured into the reactor and heated to the reaction temperature of $60^{\circ} \mathrm{C}$. 
The transesterification reaction started when methanolic solution of potassium hydroxide was added.

Because the acid number was different in each experiment, the amount of used potassium hydroxide in methanol had to respect this fact. To keep the constant ratio of $\mathrm{KOH}$ as the catalyst to amount of batched oil, the first part of catalyst amount was fixed at 0.007 grams of $\mathrm{KOH}$ per grams of batched oil. The second part calculated from (2) is for neutralisation of fatty acids present in the batch. The amount of methanol was kept at constant molar ratio of 6:1 to oil.

After 90 minutes of vigorous mixing (400 rpm), the reaction was stopped by addition of carbon dioxide (Skopal et al., 2001).

After that, the surplus of methanol from the RRM was removed (45 minutes, 3$4 \mathrm{kPa}$, at $\left.60^{\circ} \mathrm{C}\right)$.

Before pouring into the separatory funnel, the RRM was cooled down to the laboratory temperature and then approx. $10 \mathrm{~g}$ of demineralised water was added for better separation of phases (Hájek et al., 2008). The cooling took 15 minutes and the time of homogenization after the water addition another 10 minutes of stirring (500 rpm).

Thereafter, the RRM spontaneously separated into two layers, GP and EP. After the separation was finished, both layers were separated and analyzed.

\section{Results and discussion}

Fourteen experiments with different acid number of oil (from 0.89 to $12.25 \mathrm{mg}$ $\mathrm{KOH} / \mathrm{g}$ ), were carried out. It was observed that the solution of oleic acid and oil were turbid. 
The varying acid number had no affect on conversion of oil to biodiesel and on acid number of biodiesel. In all experiments the methylesters content was in the range of $99 \pm$ $1 \%$, measured by the GC method. The triglycerides content was measured by HPLC method. The recalculated results of methylester content are in a good agreement with GC, but with lower variation $98.8 \pm 0.2 \%$. Acid numbers of methylester were smaller than 0.1 mg KOH/g. But all other measured parameters of EP and GP changed in depending on the acid number of the oil.

In the figure 1, there are depicted four dependencies of yields on the acid number: ideal yield of EP (without saponification of oil) from (7), theoretically calculated EP yield calculated by (9), experimental yield of EP and experimental yield of GP. This graph allows us to state following results. Even the theoretical ideal yield is affected by the quality of the oil. It decreases with increasing content of fatty acids in the oil. These FFAs are forming soaps with $\mathrm{KOH}$ and as polar substances increase the amount of GP. Experimental yield of EP is in good agreement with the values calculated from (9). Experimental data of EP yield decrease more rapidly than the theoretical curve. So we must calculate with much greater effect of saponification caused by FFAs content in oil. For comparison, the increasing trend in GP yield is depicted too.

Figure 2 shows the dependences of the GP main components on the acid number of the oil. Mass fractions of soaps, methylester and glycerol vary with varying acid number of the oil. Increasing mass of GP (figure 1) is caused by increasing contents of soaps and methylester. Methylester content in GP and saponification are responsible for decreasing of EP yield - see (9). Decreasing of mass fraction of glycerol can be explained by its dilution by methylester and soaps. 
Figure 3 presents soaps formation from different sources. The total mass of soaps in the reaction mixture is given by formula (3), the part of soaps formed by neutralisation of free fatty acids, was calculated according to the formula (1). The difference between total mass of soaps and soaps produced from FFAs must come from the saponification of oils formula (4). As figure 3 shows, these experimental dependences have linear trend. The reason is probably in the important role of water present in the RRM, because water accelerates the saponification reaction, see reaction scheme in the figures 7 and 8 in (Mittelbach and Remschmidt, 2004). The water is always produced by neutralization and it is contained in all reaction components.

The mass fractions of potassium carbonate and potassium hydrogen carbonate in GP exponentially decrease with increasing acid number of the oil (figure 4), because still more $\mathrm{KOH}$ is consumed for saponification and because the amount of GP is increasing. Presence of these two forms of carbonate is a proof that there is still present a catalyst in the final RRM.

Density and kinematic viscosity of GP are the most relevant characteristics for the perfect separation of EP from GP. Samples with high density and low viscosity of GP separates from EP much faster (i. e. separation in hours) then samples with opposite characteristics (i. e. complete separation lasts days). The density decreases monotonously with higher acid number of the oil. Kinematic viscosity shows at first the exponential growth, reaches its maximum and then significantly decreases.

It is possible to compare the course of viscosity of GP on acid number of the oil (figure 5) with the courses of mass fractions of soaps and methylester in GP (figure 2). The maximum difference between soaps concentration and methylesters concentration corresponds to the maximum on the viscosity curve. Therefore the higher soaps content is 
responsible for higher viscosity and higher methylester content in GP. But, on the other hand, the higher methylester content lowers viscosity of GP.

\section{Conclusions}

The acid number of oil was artificially increased by the addition of oleic acid. Then, the oil was used for methanolysis (molar ratio 6:1 to oil) under the potassium hydroxide catalysis. The dose of the catalyst $\mathrm{KOH}$ was calculated with respect to different acid numbers of the used oil to keep the catalytic concentration constant ( $7 \mathrm{mg} / \mathrm{g}$ of oil). The reaction was stopped by gaseous $\mathrm{CO}_{2}$. The obtained products EP and GP were analyzed and the results discussed. There were no differences in the oil conversion and the acid numbers of biodiesel, but the mass of soap increased much more than it would correspond to soaps originated from the free fatty acids neutralization.

The high acid number of the oil decreases the methylester yield not only by higher saponification of the oil, but also because more methylester passes to the glycerol phase.

In economical aspects, the use of oils with a high acid number for basically catalyzed biodiesel production is debatable. Higher catalyst request, longer separation time and lower methylester yield are substantial disadvantages of this technology.

Some theoretical calculations were derived for experimental data evaluation and discussion.

\section{Acknowledgements}

This work has been funded by the research project MŠM 0021627502 of the Czech Ministry of Youth and Sport. 


\section{Nomenclature}

\begin{tabular}{|c|c|}
\hline AL & apolar layer \\
\hline an & acid number \\
\hline$C_{i}$ & molar concentration of the $i$ \\
\hline EP & ester phase \\
\hline FFA & free fatty acid \\
\hline GP & glycerol phase \\
\hline ME & methylester \\
\hline$m_{\mathrm{EP}}^{t, \text { id }}$ & theoretical mass of the EP at ideal conditions, without saponification \\
\hline$m_{\mathrm{FFA}}^{\text {start }}$ & mass of FFA present in the RO \\
\hline$m_{\mathrm{GP}}^{\text {sample1 }}$ & mass of the first sample of the GP \\
\hline$m_{\mathrm{GP}}^{\text {sample2 }}$ & mass of the second sample of the GP \\
\hline$M_{i}$ & molar weight of the $i$ \\
\hline$m_{i}$ & mass of $i$ \\
\hline$m_{i}^{j}$ & mass of $i$ in the $j$ phase \\
\hline$m_{\mathrm{KOH}}^{\text {neut. }}$ & mass of $\mathrm{KOH}$ for neutralisation of the FFA \\
\hline$m_{\mathrm{ME}}^{t}$ & theoretically calculated mass of the ME in the experiment \\
\hline$m_{\mathrm{N}}$ & mass of the oil for transesterification \\
\hline$m_{\mathrm{S}}^{\text {start }}$ & mass of soaps formed by neutralisation of the FFA \\
\hline$m_{\mathrm{s}}^{\mathrm{r}}$ & mass of soaps arised during the reaction \\
\hline$m_{\mathrm{TG}}^{\text {sap. }}$ & mass of triglycerides being saponificated \\
\hline
\end{tabular}




$\begin{array}{ll}p & \text { atmospheric pressure } \\ R & \text { universal gas constant } \\ \text { RO } & \text { rapeseed oil } \\ \text { S } & \text { raw reaction mixture } \\ T & \text { soaps } \\ \text { TG } & \text { triglyceride } \\ V_{1} & \text { the first volume of } \mathrm{HCl} \text { at titration } \\ V_{2} & \text { the second volume of } \mathrm{HCl} \text { at titration } \\ V_{i} & \text { volume of the } i \\ \xi_{i} & \text { mass fraction of the } i \\ \xi_{i}^{j} & \end{array}$




\section{References}

Altın, R., Çetinkaya, S., Yücesu, H. S., 2001. The potential of using vegetable oil fuels as fuel for diesel engines. Energy Conversion and Management 42, 529-538.

Demirbas, A., 2008. Studies on cottonseed oil biodiesel prepared in non-catalytic SCF conditions. Bioresource Technology 99, 1125-1130.

Hájek, M., Skopal, F., Machek, J., 2008. Simplification of separation of the reaction mixture after transesterification of vegetable oil. Eur. J. Lipid Sci. Technol. 110, 347-350

Iso, M., Chen, B., Eguchi, M., Kudo, T., Shrestha, S., 2001. Production of biodiesel fuel from triglycerides and alcohol using immobilized lipase. Journal of Molecular Catalysis B: Enzymatic 16, 53-58.

Jacobson, K., Gopinath, R., Meher, L. C., Dalai, A. K., 2008. Solid acid catalyzed biodiesel production from waste cooking oil. Applied Catalysis B: Environmental 85, 86-91.

Jureček, M., 1957. Organická analysa II, CSAV Praha.

Kegl, B., 2008. Effects of biodiesel on emissions of a bus diesel engine. Bioresource Technology 99, (4) 863-873. 
Komers, K., Stloukal, R., Machek, J., Skopal, F., Komersová, A., 1998. Biodiesel fuel from rapeseed oil, methanol, and $\mathrm{KOH}$. Analytical methods in research and production. Fett/Lipid 100, 507-512.

López, D. E., Goodwin Jr., J. G., Bruce, D. A., Lotero, E. , 2005. Transesterification of triacetin with methanol on solid acid and base catalysts. Applied Catalysis A: Gen 295, 97105.

Marchetti, J. M., Errazu, A. F, 2008. Comparison of different heterogeneous catalysts and different alcohols for the esterification reaction of oleic acid. Fuel 87, 3477-3480.

Mittelbach, M., Remschmidt, C., 2004. Biodiesel the comprehensive handbook, first ed. Boersedruck, Vienna (Austria).

Skopal, F., Komers, K., Machek, J.: Czech Republic patent 289417 (2001).

Vicente, G., Martínez, M., Aracil, J., 2004. Integrated biodiesel production: a comparison of different homogeneous catalysts systems. Bioresource Technology 92, 297-305. 


\section{Figure 1:}

Yields analysis as functions of acid number of the oil. 
Figure 2:

GP analysis I - Mass fractions of glycerol, soaps and methylester as functions of acid number of the oil. 


\section{Figure 3:}

Mass balance of soaps as functions of acid numer of the oil. Absolut mass of soaps found in GP per mass of the oil is labeled by (o), theoretical mass of soaps calculated from FFAs (dashed line). Diffrence between these two masses is the amount of soaps arised from oil saponification (thick full line). 


\section{Figure 4:}

GP analysis II - Mass fractions of inactive forms of catalyst (potassium carbonate $(+)$ and potassium hydrogen carbonate(o)) as functions of acid number of the oil. 


\section{Figure 5:}

GP analysis III - Dependences of density (+) and kinematic viskosity at $40{ }^{\circ} \mathrm{C}(\boldsymbol{\bullet})$ of GP on the acid number of the oil. 